\title{
DEMANDA ENERGÉTICA DA SEMEADURA DO MILHO EM DIFERENTES MANEJOS DO SOLO E ESPAÇAMENTOS ENTRE LINHAS
}

\author{
BERTOLINI, Erick Vinicius ${ }^{1}$ \\ GAMERO, Carlos Antonio ${ }^{2}$ \\ SALATA, Ariane da Cunha ${ }^{3}$ \\ PIFFER, Cassio Roberto
}

RESUMO: As diferentes condições da superfície do solo inerente a cada sistema de manejo podem afetar a demanda energética da operação de semeadura devido à complexidade de suas interações com o conjunto trator/semeadora. Assim sendo, o objetivo deste trabalho foi avaliar o efeito de dois sistemas de manejo do solo e dois espaçamentos entre linhas na demanda energética da operação de semeadura da cultura do milho. $O$ experimento foi conduzido na Faculdade de Ciências Agronômicas (FCA) da Universidade Estadual Paulista (UNESP), campus de Botucatu-SP, em Nitossolo Vermelho Distroférrico. O delineamento experimental utilizado foi de blocos ao acaso com parcelas subdivididas e quatro repetições. As parcelas foram constituídas pelos sistemas de manejo do solo (plantio direto e preparo reduzido - escarificação) e as subparcelas pelos espaçamentos entre linhas $(0,90 \mathrm{~m}$ e $0,45 \mathrm{~m})$. Os resultados obtidos foram submetidos ao teste de Tukey a $5 \%$ de probabilidade para comparar as médias. As análises estatísticas demonstraram que a semeadura do milho no sistema plantio direto requer menor força na barra de tração, menor demanda de potência média, menor consumo específico de energia por área, menor consumo de combustível por hora e por área. A semeadura do milho no espaçamento de 0,45 m entre linhas exige maior força de tração na barra, maior demanda de potência, maior consumo específico de energia por área e maior consumo horário de combustível.

Termos de indexação: Zea mays. Plantio direto. Força de tração. Potência na barra. Consumo de combustível.

\section{ENERGY DEMAND OF THE CORN SOWING IN DIFFERENT SOIL TILLAGES AND ROW SPACINGS}

SUMMARY: The different soil surface conditions associated with each tillage system can change the sowing energy demand due to the complexity of their interactions with the tractor/seeder. Therefore, the objective of this work was to evaluate the effect of two soil tillage systems and two row spacings on energy demand of the corn sowing. The experiment was carried out at the "Faculdade de Ciências Agronômicas" (FCA) of the "Universidade Estadual Paulista" (UNESP), Botucatu-SP campus, in a Dystric Nitosol. The experimental design was in randomized blocks with split-plots and four repetitions. The main plots consisted of two soil tillage systems (no-tillage and reduced tillage - chisel plow) and the split-plots of row spacings $(0.90 \mathrm{~m}$ and $0.45 \mathrm{~m})$. Obtained results were analyzed by Tukey test at $5 \%$ of probability for comparing averages. Statistical analysis showed that corn sowing in no-tillage system requires lower traction force, bar power demand, area energy specific consumption, hourly and area fuel consumption. Corn sowing in $0.45 \mathrm{~m}$ row spacing demands higher traction force, bar power demand, area energy specific consumption and hourly fuel consumption.

Keywords: Zea mays. No-tillage. Traction force. Bar power. Fuel consumption.

\section{INTRODUÇÃO}

Independentemente do sistema de produção agrícola, a etapa referente ao preparo do solo e à implantação das culturas é uma das mais importantes, devido não somente ao seu elevado custo operacional, em relação ao custo total do empreendimento, como também porque, sendo a inicial, refletirá

\footnotetext{
${ }^{1}$ Engenheiro Agrônomo, Mestre e Doutor em Agronomia

${ }^{2}$ Professor Doutor Titular do Departamento de Engenharia Rural da UNESP - FCA

${ }^{3}$ Pós-Doutoranda do Curso de Pós-Graduação em Agronomia/Horticultura da UNESP - FCA
} 
no desenvolvimento e na produtividade das culturas (GAMERO, 1985).

Os sistemas de manejo do solo podem ser classificados como: Convencional, caracterizado normalmente por uma aração seguida de duas gradagens leves (ORTIZ-CAÑAVATE, 1980), tendo como principal característica o alto grau de mobilização e desagregação do solo; Reduzido, que tem como objetivo a menor manipulação do solo com redução do número de operações para o seu preparo, sendo o escarificador, conjugado com disco de corte de palhada e rolo destorroador, considerado o equipamento ideal para essa modalidade de preparo (FURLANI et al., 2004); Plantio Direto, que tem como princípio a semeadura diretamente em solo não revolvido, no qual a mobilização é efetuada apenas na linha de semeadura mantendo os restos de cultura anterior na superfície (JONES et al. 1968). No Brasil, o plantio direto tem se expandido devido às suas vantagens nos aspectos econômicos e ambientais, visando a maior conservação do solo e diminuição do tráfego de máquinas agrícolas (FURLANI et al., 2005a).

Além de favorecer o pleno desenvolvimento das culturas, o preparo do solo, tem como finalidade proporcionar condições adequadas para que as máquinas utilizadas desde a semeadura até a colheita possam apresentar um bom desempenho (MAZUCHOWSKI; DERPSCH, 1984). É de se esperar que as diferenças ocasionadas pelos sistemas de manejo na estrutura, no teor de água, na distribuição do tamanho dos agregados, na resistência à penetração, na porosidade e na densidade do solo, também possam afetar o desempenho operacional do conjunto trator/semeadora, tornando-se fundamental avaliar como essas máquinas trabalham em diferentes condições de solo.

Nesse sentido, Furlani; Lopes; Silva(2005b) observaram que no preparo reduzido do solo, a operação de semeadura do milho apresentou maior consumo de combustível, menor velocidade de deslocamento, menor capacidade de campo efetiva e maior patinagem em relação ao sistema plantio direto, enquanto Mahl et al. (2004), não encontraram diferenças significativas na força de tração, potência na barra, consumo de combustível e capacidade de campo específica entre o sistema plantio direto e preparo reduzido.

Outro fator que pode influir na demanda energética na operação de semeadura do milho é a redução do espaçamento entre linhas, uma vez que a adoção dessa técnica, mantendo a mesma largura de trabalho da semeadora, utiliza-se maior número de unidades de semeadura na máquina em relação ao espaçamento convencional de $0,90 \mathrm{~m}$. Modolo et al. (2005) relataram que a força de tração média na barra teve um incremento de $131,9 \%$ com o aumento do número de linhas de semeadura de uma para cinco.

Nesse contexto, nota-se a importância de trabalhos que visem identificar o desempenho energético da operação de semeadura do milho em relação às interações existentes entre os sistemas de manejo do solo e os espaçamentos entre linhas da cultura. Dessa forma, o objetivo deste trabalho foi avaliar a demanda energética da operação de semeadura da cultura do milho nos espaçamentos de $0,90 \mathrm{~m}$ e $0,45 \mathrm{~m}$ entre linhas em dois sistemas conservacionistas de manejo do solo.

\section{MATERIAL E MÉTODOS}

O experimento foi realizado em novembro de 2006, na Fazenda Experimental Lageado, pertencente à Faculdade de Ciências Agronômicas da UNESP, localizada no município de Botucatu - SP. A localização geográfica está definida pelas coordenadas 22 $51^{\prime} 22^{\prime \prime}$ de Latitude Sul e $48^{\circ} 26^{\prime} 08^{\prime \prime}$ de Longitude Oeste de Greenwich, com altitude média de $770 \mathrm{~m}$, declividade média de $6 \%$ e exposição face oeste. O clima predominante no município, de acordo com a classificação de Köppen, é tipo Cfa, temperado quente (mesotérmico) úmido, e a temperatura média do mês mais quente é superior a $22^{\circ} \mathrm{C}$ (CUNHA; MARTINS, 2009).

A área na qual foi instalado o experimento vem sendo cultivada desde o ano de 2000 com o 
sistema plantio direto, realizando-se a rotação soja e milho no verão e pousio de inverno. A cobertura do solo, composta por restos da cultura do milho e pela vegetação espontânea, forneceu $9.895 \mathrm{~kg} \mathrm{ha}^{-1} \mathrm{de}$ massa seca e recobriu 96,0 \% da superfície do solo, sem diferir significativamente (Tukey a 5\%) entre as parcelas, indicando homogeneidade da área experimental antes da instalação dos tratamentos. O manejo da vegetação espontânea foi realizado por meio da aplicação de herbicida e posteriormente por picador de palhas.

O solo da área experimental é um Nitossolo Vermelho Distroférrico (EMBRAPA, 2006), do qual algumas características são apresentadas na Tabela 1.

Tabela 1. Características do solo da área experimental na camada de $0-0,20 \mathrm{~m}$ de profundidade

\begin{tabular}{lr}
\hline Características do solo & \\
\hline Teor de argila $\left(\mathrm{g} \mathrm{kg}^{-1}\right)$ & 456 \\
Teor de silte $\left(\mathrm{g} \mathrm{gk}^{-1}\right)$ & 315 \\
Teor de areia $\left(\mathrm{g} \mathrm{kg}^{-1}\right)$ & 229 \\
Classe textural & Argilosa \\
Matéria orgânica $\left(\mathrm{g} \mathrm{dm}^{-3}\right)$ & 32 \\
Limite de liquidez (\%) & 46,76 \\
Limite de plasticidade $(\%)$ & 32,51 \\
Índice de plasticidade & 14,25 \\
Limite de contração $(\%)$ & 19,89 \\
Densidade do solo $\left.(\mathrm{Mg} \mathrm{m})^{-3}\right)$ & 1,34 \\
Densidade de partículas $\left(\mathrm{Mg} \mathrm{m}^{-3}\right)$ & 2,92 \\
Teor de água $(\%)$ no momento da semeadura & 28,22 \\
Teor de água crítico $(\%)-$ Ensaio de Proctor & 29,67 \\
Densidade máxima do solo $\left(\mathrm{Mg} \mathrm{m}^{-3}\right)$ - Ensaio de Proctor & 1,53 \\
\hline
\end{tabular}

O delineamento experimental utilizado foi de blocos ao acaso com parcelas subdivididas e quatro repetições, no qual as parcelas foram constituídas pelos sistemas de manejo do solo e as subparcelas pelos espaçamentos entre linhas. As parcelas e subparcelas possuíam dimensões de $20 \mathrm{~m}$ de comprimento, sendo separadas por carreadores de $10 \mathrm{~m}$ de largura que auxiliaram no trânsito, manobras e estabilização operacional do conjunto motomecanizado utilizado na execução do experimento. Os sistemas de manejo do solo empregados foram: reduzido, por meio de escarificação do solo até a profundidade entre $0,25 \mathrm{e}$ $0,30 \mathrm{~m}$, e plantio direto. Os espaçamentos entre linhas adotados na cultura do milho foram: $0,90 \mathrm{~m}$ e 0,45 $\mathrm{m}$.

Para o preparo reduzido do solo, foi empregado um escarificador da marca Jan, modelo Jumbo Matic JMAD-7, de arrasto, com mecanismo de levante no sistema hidráulico, equipado com sete hastes parabólicas de 0,43 m de comprimento, espaçadas a 0,40 m, ponteiras reversíveis estreitas de 0,05 $\mathrm{m}$ de largura, com ângulo de penetração de $24^{\circ}$, dotadas de sistema de segurança por molas planas, discos de corte de 18" colocados à frente de cada haste e dois rolos destorroadores/niveladores, de ação independente, acoplados a parte posterior, cada um medindo $1,5 \mathrm{~m}$ de largura, $0,40 \mathrm{~m}$ de diâmetro e 10 barras transversais com saliências, dispostas em forma helicoidal e com regulagem de pressão sobre o solo.

Nas avaliações de demanda energética utilizou-se uma semeadora-adubadora de precisão, marca Marchesan, modelo PST $^{2} 8$ D44 para plantio direto, de arrasto. Devido à avaliação do desempenho do conjunto trator/semeadora-adubadora, foi necessário manter a mesma largura de trabalho entre os diferentes espaçamentos entre linhas avaliados. Assim sendo, foram utilizadas três unidades de semeadura 
espaçadas a $0,90 \mathrm{~m}$ e seis espaçadas a $0,45 \mathrm{~m}$. Afim de proporcionar a mesma profundidade de deposição de sementes e adubos, a regulagem da semeadora-adubadora foi realizada especificamente para cada condição de manejo do solo e espaçamento entre linhas. Os reservatórios de sementes e fertilizantes foram abastecidos a 50,0 \% de sua capacidade. As avaliações foram realizadas com uma única passada da máquina em cada subparcela. Os principais parâmetros de configuração da semeadora-adubadora selecionados para os testes encontram-se no Tabela 2.

Tabela 2. Configurações da semeadora-adubadora PST $^{2} 8$ D44 utilizada nas avaliações da demanda energética na operação de semeadura do milho

\begin{tabular}{lcc}
\hline Parâmetro/função & Características \\
\hline Número de unidades de semeadura & 6 linhas & 3 linhas \\
Espaçamento das unidades de semeadura & $0,45 \mathrm{~m}$ & $0,90 \mathrm{~m}$ \\
Largura útil de plantio & $2,70 \mathrm{~m}$ \\
Capacidade dos depósitos de adubo & $725 \mathrm{~kg}$ \\
Capacidade dos depósitos de semente & \multicolumn{2}{c}{$40 \mathrm{~kg}$ cada } \\
Corte da cobertura & disco liso com diâmetro de 18" \\
Sulcador de fertilizantes & disco duplo desencontrado com diâmetro de 15" \\
Sulcador de sementes & disco duplo desencontrado com diâmetro de 15" \\
Posição dos sulcadores & \multicolumn{2}{c}{ alinhados } \\
Compactação do sulco & \multicolumn{2}{c}{ duas rodas estreitas em "V" } \\
Controle da profundidade & rodas de borracha laterais aos discos duplos \\
Dosador de sementes & disco horizontal alveolado com 28 furos \\
Dosador de fertilizantes & condutor helicoidal com passo de 2" \\
Pneus & 650-16 - 10 Lonas (70 Lbs/pol2) \\
Peso total aproximado & 1774 kg \\
\hline
\end{tabular}

A semeadora-adubadora foi tracionada por um trator marca John Deere, modelo 6.600, com tração dianteira auxiliar (TDA), motor John Deere de 6 cilindros e $89 \mathrm{~kW}(121 \mathrm{cv})$ de potência e massa de 4.650 $\mathrm{kg}$, operando na marcha 2B a $2100 \mathrm{rpm}$ (540 rpm na TDP). $\mathrm{O}$ trator estava equipado com pneus traseiros R1 23.1-30 e pneus dianteiros R1 14.9-26, com pressão de inflação de 82,7 kPa (12 psi) e $110 \mathrm{kPa}$ (16 psi), respectivamente, conforme recomendações do fabricante.

A obtenção das variáveis estudadas da demanda energética se deu por meio de um sistema de aquisição de dados computadorizado da marca Campbell Scientific, modelo Micrologger 21X, para monitorar e exibir os dados provenientes dos equipamentos instalados no trator (célula de carga e fluxômetro). Os dados foram transferidos em tempo real para um módulo de armazenamento externo denominado "Storage module SM196" e posteriormente deste para um computador portátil, marca Compaq, modelo 1200, para análise dos dados coletados no campo.

Determinou-se a força de tração com o auxílio de um transdutor de força (célula de carga), da marca Sodmex, modelo N-400, com capacidade de $100 \mathrm{kN}$ e sensibilidade de $1,998 \mathrm{mV} \mathrm{V}^{-1}$, instalada entre a barra de tração do trator e o cabeçalho da semeadora-adubadora, em um suporte fixo no trator de forma a mantê-lo em posição horizontal e evitar fortes impactos. A força média de tração na barra foi determinada pela média dos valores armazenados e a força de tração máxima, ou pico de força, correspondeu ao máximo valor de força de tração obtido pelo sistema de aquisição de dados, durante o percurso de deslocamento na área experimental.

A velocidade de deslocamento foi obtida da relação entre o comprimento das subparcelas pelo tempo gasto para percorrê-las, que foi determinado indiretamente por meio da frequiência de aquisição de 
dados $(10 \mathrm{~Hz})$ do Micrologger 21X. A potência exigida na barra de tração foi determinada por meio do produto da força de tração e a velocidade de deslocamento. A capacidade de campo efetiva foi calculada pelo produto da largura útil de trabalho da semeadora e a velocidade de deslocamento. O tempo efetivo demandado foi determinado pelo inverso da capacidade de campo efetiva.

O consumo de combustível foi obtido por meio de um fluxômetro, marca Flowmate oval, modelo Oval M-III, com precisão de $0,01 \mathrm{~mL}$, instalado em um suporte próximo ao filtro de combustível do trator. O gerador emitiu ao sistema de aquisição de dados uma unidade de pulso a cada $\mathrm{mL}$ de combustível que passou pelo mesmo. O consumo horário de combustível foi calculado pela relação entre o número total de pulsos pelo tempo gasto para percorrer as subparcelas e o consumo de combustível por área foi calculado pelo produto do consumo horário de combustível e o tempo efetivo demandado.

Os dados obtidos foram submetidos ao teste de Tukey a $5 \%$ de probabilidade para comparar as médias entre sistemas de manejo do solo, espaçamentos entre linhas e nos desdobramentos das interações entre esses fatores com o auxílio do programa estatístico Sisvar.

\section{RESULTADOS E DISCUSSÃO}

A velocidade média de deslocamento obtida na operação de semeadura do milho, em ambos espaçamentos, não diferiu estatisticamente em função dos sistemas de manejo do solo (Tabela 3). Nagaoka et al. (2006) também não notou influência dos sistemas de manejo do solo na velocidade de semeadura enquanto que Furlani et al. (2005b) relataram maior velocidade média na semeadura no sistema de plantio direto em relação ao preparo do solo com escarificador. Os espaçamentos entre linhas também não influíram na velocidade média da operação de semeadura do milho, independentemente do sistema de manejo empregado.

Tabela 3. Velocidade média de deslocamento $\left(\mathrm{km} \mathrm{h}^{-1}\right)$, força média e máxima $(\mathrm{kN})$ e potência média e máxima $(\mathrm{kW})$ na barra de tração na operação de semeadura do milho em dois sistemas de manejo do solo e dois espaçamentos entre linhas. UNESP -FCA, Botucatu - SP, 2006.

(Continua)

\begin{tabular}{|c|c|c|}
\hline \multicolumn{3}{|c|}{ Velocidade média de deslocamento $\left(\mathrm{km} \mathrm{h}^{-1}\right)$} \\
\hline \multirow{2}{*}{ Espaçamento entre linhas } & \multicolumn{2}{|c|}{ Sistemas de manejo do solo } \\
\hline & PD & PR \\
\hline 90 & $5,07 \mathrm{aA}$ & $5,06 \mathrm{aA}$ \\
\hline 45 & $5,10 \mathrm{aA}$ & $5,01 \mathrm{aA}$ \\
\hline \multicolumn{3}{|c|}{ Força média $(k N)$ na barra de tração } \\
\hline \multirow{2}{*}{ Espaçamento entre linhas } & \multicolumn{2}{|c|}{ Sistemas de manejo do solo } \\
\hline & PD & PR \\
\hline 90 & $6,12 \mathrm{bB}$ & $7,64 \mathrm{bA}$ \\
\hline 45 & $8,23 \mathrm{aB}$ & $10,34 \mathrm{aA}$ \\
\hline \multicolumn{3}{|c|}{ Força máxima $(k N)$ na barra de tração } \\
\hline
\end{tabular}

Espaçamento entre linhas

Sistemas de manejo do solo

\begin{tabular}{ccc}
\cline { 2 - 3 } Espaçamento entre linhas & PD & PR \\
\hline 90 & $7,84 \mathrm{bB}$ & $9,98 \mathrm{bA}$ \\
45 & $10,21 \mathrm{aB}$ & $12,88 \mathrm{aA}$
\end{tabular}


Tabela 3. Velocidade média de deslocamento $\left(\mathrm{km} \mathrm{h}^{-1}\right)$, força média e máxima $(\mathrm{kN})$ e potência média e máxima $(\mathrm{kW})$ na barra de tração na operação de semeadura do milho em dois sistemas de manejo do solo e dois espaçamentos entre linhas. UNESP -FCA, Botucatu - SP, 2006.

(Conclusão)

\begin{tabular}{|c|c|c|}
\hline \multicolumn{3}{|c|}{ Potência média $(\mathrm{kW})$ na barra de tração } \\
\hline \multirow{2}{*}{ Espaçamento entre linhas } & \multicolumn{2}{|c|}{ Sistemas de manejo do solo } \\
\hline & $\mathrm{PD}$ & PR \\
\hline 90 & $8,62 \mathrm{bB}$ & $10,74 \mathrm{bA}$ \\
\hline 45 & $11,67 \mathrm{aB}$ & $14,38 \mathrm{aA}$ \\
\hline \multicolumn{3}{|c|}{ Potência máxima $(\mathrm{kW})$ na barra de tração } \\
\hline \multirow{2}{*}{ Espaçamento entre linhas } & \multicolumn{2}{|c|}{ Sistemas de manejo do solo } \\
\hline & $\mathrm{PD}$ & PR \\
\hline 90 & $11,03 \mathrm{bA}$ & $14,06 \mathrm{bA}$ \\
\hline 45 & $14,47 \mathrm{aB}$ & $17,92 \mathrm{aA}$ \\
\hline
\end{tabular}

Médias seguidas de mesma letra minúscula na coluna ou de mesma letra maiúscula na linha não diferem entre si pelo teste de Tukey a $5 \%$ de probabilidade.

Tanto no sistema plantio direto como no preparo reduzido, quando se utilizou o espaçamento de 0,45 m entre linhas, maior foi a exigência de força na barra de tração, média e máxima (Tabela 3), diferindo-se estatisticamente do esforço obtido com espaçamento de $0,90 \mathrm{~m}$. Este fato decorreu do maior número de unidades de semeadura utilizado no espaçamento de $0,45 \mathrm{~m}$, que além de adicionar peso à semeadora-adubadora, também acrescentou órgãos ativos para corte da palhada e abertura de sulcos no solo para deposição de sementes e adubos, aumentou o número de rodas de controle de profundidade e de rodas compactadoras, o que, conseqüientemente, ocasionou maior resistência ao rolamento. Estes resultados são conflitantes com os de Silva (2004), que observou diferenças apenas no preparo reduzido, com menor força média no espaçamento de $0,45 \mathrm{~m}$. No entanto, esse autor trabalhou com quatro unidades de semeadura para o espaçamento de $0,90 \mathrm{~m}$ entre linhas e seis para o espaçamento de $0,45 \mathrm{~m}$, elevando o número de unidades de semeadura em 50,0\%, enquanto que nesse experimento foram utilizadas três unidades espaçadas a $0,90 \mathrm{~m}$ e seis a $0,45 \mathrm{~m}$, representando um acréscimo de 100,0 \%, o que pode justificar a discrepância entre os dois estudos. Modolo et al. (2005) também observaram aumento da força de tração com o acréscimo de unidades de semeadura, mas, diferentemente deste estudo, os autores mantiveram fixo o espaçamento entre linhas em $0,45 \mathrm{~m}$.

Observa-se ainda na Tabela 3 que o sistema plantio direto exigiu menor força, média e máxima respectivamente, na barra de tração em ambos os espaçamentos entre linhas, tendo diferido dos valores obtidos no preparo reduzido. O maior requerimento de esforço de tração com a semeadora no preparo reduzido pode ser atribuída à rugosidade superficial do solo decorrente da mobilização realizada pela operação de escarificação. Além disso, o empolamento do solo no preparo reduzido resultou no afundamento dos rodados da semeadora e, conseqüentemente, aumentou sua resistência ao rolamento.

Outro fator a se considerar é que os mecanismos sulcadores para deposição de adubos e sementes foram constituídos por discos duplos defasados, o que pode ter facilitado o rolamento no plantio direto, no qual a maior estruturação do solo oferece maior resistência à penetração em relação ao solo escarificado. Levien et al. (2011) verificaram que a utilização do sulcador tipo haste requereu 32,0 \% a mais na força média de tração em relação ao uso do sulcador de discos na semeadura direta em nível, enquanto que Silva; Benez (2005) observaram um aumento de 97,4\%.

Em ambos os sistemas de manejo do solo, quando se utilizou o espaçamento de 0,45 m entre 
linhas, maior foi a exigência de potência, média e máxima (Tabela 3), diferindo-se estatisticamente da obtida com espaçamento de $0,90 \mathrm{~m}$.

Independentemente do espaçamento entre linhas adotado, verifica-se que o sistema plantio direto requereu menor potência média na barra de tração, diferindo-se estatisticamente dos valores observados no preparo reduzido, concordando com os resultados obtidos por e Furlani; Gamero; Levien (2002), contudo divergindo de Mahl et al. (2004) e Furlani et al. (2005a), que não observaram diferenças no requerimento de potência em função dos sistemas de manejo do solo.

A potência máxima requerida não diferiu estatisticamente em virtude dos sistemas de manejo do solo no espaçamento de $0,90 \mathrm{~m}$, porém foi $27,4 \%$ maior no preparo reduzido. No espaçamento de $0,45 \mathrm{~m}$, os dados obtidos revelaram diferenças estatísticas na potência máxima requerida em razão dos sistemas de manejo, tendo os tratamentos com escarificação mostrado valores superiores àqueles observados no plantio direto.

Constata-se que os resultados encontrados no requerimento de potência se devem principalmente às diferenças observadas na força de tração na barra.

É importante ressaltar que a operação de semeadura do milho exigiu uma potência máxima de 18 kW, aproximadamente, o que segundo Casão Junior; Araujo; Ralisch (2000), considerando com 70,0 \% de eficiência de tração e $10,0 \%$ de perda de potência entre o motor e o eixo das rodas motoras do trator, representa $28,6 \mathrm{~kW}$ de potência requerida no motor, e o trator utilizado tinha potência de $89 \mathrm{~kW}$, ou seja, foi exigido do trator apenas $32,0 \%$ de sua capacidade, evidenciando o seu superdimensionamento para a realização desta operação.

Devido à manutenção da largura de trabalho da semeadora-adubadora para todos os tratamentos $(2,70 \mathrm{~m})$, apenas a velocidade média de deslocamento poderia influir sobre os valores da capacidade de campo efetiva. Como a velocidade não variou, a capacidade de campo efetiva obtida na operação de semeadura do milho não diferiu estatisticamente em decorrência dos sistemas de manejo do solo e espaçamentos entre linhas (Tabela 4). Da mesma forma, o tempo efetivo demandado, ou seja, o tempo consumido exclusivamente em trabalho produtivo, também não foi influenciado pelos tratamentos, uma vez que este é função inversa da capacidade de campo efetiva (Tabela 4).

Furlani et al. (2005a) verificaram maior capacidade de campo efetiva na operação de semeadura nos sistemas plantio direto e convencional, em relação ao preparo reduzido, reportando que a semeadura tem maior dificuldade em solo escarificado devido à condição de não consolidação da superfície do solo, diferindo do plantio direto que, pelo não revolvimento do solo, permanece consolidado e ainda, do preparo convencional que, após as passagens da grade niveladora, retorna a uma condição mais consolidada.

Com relação aos espaçamentos entre linhas, Silva (2004) observou uma capacidade de campo efetiva $24,5 \%$ superior com espaçamento de $0,90 \mathrm{~m}$. Entretanto, esse resultado decorreu principalmente da diferença na largura de trabalho da semeadora-adubadora para cada espaçamento, pois o autor utilizou 3,60 m para o espaçamento de $0,90 \mathrm{~m}$ e 2,70 $\mathrm{m}$ para o espaçamento de $0,45 \mathrm{~m}$. 
Tabela 4. Capacidade de campo efetiva $\left(\mathrm{ha}^{-1}\right)$, tempo efetivo demandado $\left(\mathrm{h} \mathrm{ha}^{-1}\right)$, consumo específico de energia por área $\left(\mathrm{kWh} \mathrm{ha}^{-1}\right)$, consumo horário de combustível $\left(\mathrm{L} \mathrm{h}^{-1}\right)$ e consumo de combustível por área $\left(\mathrm{L} \mathrm{ha}^{-1}\right)$ na operação de semeadura do milho em dois sistemas de manejo do solo e dois espaçamentos entrelinhas. UNESP -FCA, Botucatu - SP, 2006.

\section{Capacidade de campo efetiva $\left(h \mathbf{h}^{-1}\right)$}

\begin{tabular}{|c|c|c|}
\hline \multirow{2}{*}{ Espaçamento entre linhas } & \multicolumn{2}{|c|}{ Sistemas de manejo do solo } \\
\hline & PD & PR \\
\hline 90 & $1,37 \mathrm{aA}$ & $1,37 \mathrm{aA}$ \\
\hline 45 & $1,38 \mathrm{aA}$ & $1,35 \mathrm{aA}$ \\
\hline \multicolumn{3}{|c|}{ Tempo efetivo demandado $\left(\mathrm{h} \mathrm{ha}^{-1}\right)$} \\
\hline \multirow{2}{*}{ Espaçamento entre linhas } & \multicolumn{2}{|c|}{ Sistemas de manejo do solo } \\
\hline & PD & PR \\
\hline 90 & $0,73 \mathrm{aA}$ & $0,73 \mathrm{aA}$ \\
\hline 45 & $0,73 \mathrm{aA}$ & $0,74 \mathrm{aA}$ \\
\hline
\end{tabular}

Consumo específico de energia por área $\left(\mathrm{kWh} \mathrm{ha}^{-1}\right)$

\begin{tabular}{ccc}
\hline \multirow{2}{*}{ Espaçamento entre linhas } & \multicolumn{2}{c}{ Sistemas de manejo do solo } \\
\cline { 2 - 3 } & PD & PR \\
\hline 90 & $6,30 \mathrm{bB}$ & $7,86 \mathrm{bA}$ \\
45 & $8,47 \mathrm{aB}$ & $10,64 \mathrm{aA}$ \\
\hline
\end{tabular}

Consumo horário de combustível $\left(\mathrm{L} \mathrm{h}^{-1}\right)$

\begin{tabular}{ccc}
\hline \multirow{2}{*}{ Espaçamento entre linhas } & \multicolumn{2}{c}{ Sistemas de manejo do solo } \\
\cline { 2 - 3 } & $\mathrm{PD}$ & PR \\
\hline 90 & $8,83 \mathrm{aB}$ & $10,35 \mathrm{bA}$ \\
45 & $9,30 \mathrm{aB}$ & $11,02 \mathrm{aA}$ \\
\hline
\end{tabular}

\begin{tabular}{ccc}
\hline \multicolumn{3}{c}{ Consumo de combustível por área $\left(\mathbf{L ~ h a}^{-\mathbf{1}}\right)$} \\
\hline \multirow{2}{*}{ Espaçamento entre linhas } & \multicolumn{2}{c}{ Sistemas de manejo do solo } \\
\cline { 2 - 4 } & $\mathrm{PD}$ & $\mathrm{PR}$ \\
\hline 90 & $6,48 \mathrm{aB}$ & $7,59 \mathrm{aA}$ \\
45 & $6,76 \mathrm{aB}$ & $8,15 \mathrm{aA}$ \\
\hline
\end{tabular}

Médias seguidas de mesma letra minúscula na coluna ou de mesma letra maiúscula na linha não diferem entre si pelo teste de Tukey a $5 \%$ de probabilidade.

Nota-se que, tanto no plantio direto como no preparo reduzido, quando se utilizou o espaçamento de 0,45 m entre linhas, maior foi consumo de energia, diferindo-se estatisticamente ao verificado com espaçamento de $0,90 \mathrm{~m}$. Observa-se ainda que a semeadura realizada no sistema plantio direto consumiu menos energia em ambos os espaçamentos entre linhas, tendo diferido dos valores obtidos no preparo reduzido. Furlani et al. (2004) notaram um aumento de 13,0 \% no consumo de energia na operação de semeadura no solo preparado com escarificador, em relação ao plantio direto e preparo convencional.

As diferenças verificadas nos resultados apresentados para consumo específico de energia por área, obtidos na operação de semeadura do milho nos diferentes sistemas de manejo do solo, espaçamentos entre linhas e nas interações entre estes fatores, se devem, principalmente, à potência requerida na barra. 
O consumo horário de combustível na operação de semeadura do milho em ambos os espaçamentos entre linhas foi influenciado pelos manejos do solo, com menor dispêndio no plantio direto (Tabela 4). Este resultado pode ser atribuído ao maior esforço e potência exigidos pela semeadora devido à maior resistência ao rolamento em condições de solo escarificado.

Também Furlani et al. (2008) observaram que o consumo horário de combustível variou em função da força e da potência na barra de tração, tendo sido maior no plantio direto em relação ao preparo convencional do solo, porém com a utilização de disco duplo desencontrado para deposição de adubo no sistema convencional e haste sulcadora no plantio direto, o que pode ter sido preponderante em seus resultados.

Ressalta-se ainda que, no geral, a semeadura do milho no solo escarificado elevou o consumo de combustível em 1,62 L por hora, o que representa um consumo 17,9 \% superior em relação ao plantio direto do milho.

Constata-se também na Tabela 4 que apenas no preparo reduzido o consumo horário de combustível foi influenciado pelos espaçamentos entrelinhas, com maior gasto na semeadura realizada com espaçamento de $0,45 \mathrm{~m}$.

O consumo de combustível por área na operação de semeadura do milho não diferiu em função dos espaçamentos entre linhas, tendo sido influenciado apenas pelos sistemas de manejo do solo (Tabela 4). Pode-se observar que, tanto no espaçamento de $0,90 \mathrm{~m}$ como no de $0,45 \mathrm{~m}$, o plantio direto proporcionou menor consumo de combustível por área semeada.

Com base nos resultados apresentados, evidencia-se que a semeadura do milho no sistema plantio direto e no espaçamento de $0,90 \mathrm{~m}$ proporciona menor demanda energética. No entanto, cabe salientar que em diversos trabalhos há relatos de que a adoção do espaçamento reduzido na cultura do milho promove incrementos na produtividade, o que dependendo da situação, pode compensar seu maior requerimento energético.

\section{CONCLUSÃO}

A semeadura da cultura do milho no sistema plantio direto requer menor consumo de combustível, menor força e potência média na barra de tração e menor consumo específico de energia por área.

A redução do espaçamento entre linhas, com conseqüente aumento do número de unidades de semeadura, eleva o consumo horário de combustível, a exigência de força e potência na barra e o consumo específico de energia por área.

A combinação plantio direto e espaçamento de $0,90 \mathrm{~m}$ entre linhas proporciona menor demanda energética na operação de semeadura do milho em relação às demais combinações.

\section{REFERÊNCIAS}

CASÃO JUNIOR, R.; ARAUJO, A.G.; RALISCH, R. Desempenho da semeadora-adubadora Magnum 2850 em plantio direto no basalto paranaense. Pesquisa Agropecuária Brasileira, Brasília, v.35, n.3, p.523-532, 2000.

CUNHA, A.R.; MARTINS, D. Classificação climática para os municípios de Botucatu e São Manuel, SP. Irriga, Botucatu, v.14, n.1, 2009. Disponível em: 〈http://200.145.140.50/ojs1/viewissue.php?id=33 >. Acesso: em 13 maio 2011.

EMBRAPA - EMPRESA BRASILEIRA DE PESQUISA AGROPECUÁRIA. Centro Nacional de Pesquisa de Solos. Sistema brasileiro de classificação de solos. 2.ed. Rio de Janeiro: Embrapa-SPI, 2006. 306p. 
FURLANI, C.E.A.; GAMERO, C.A.; LEVIEN, R. Semeadora-adubadora de fluxo contínuo: Desempenho operacional em função de diferentes condições de preparo e cobertura do solo. Engenharia Agrícola, Jaboticabal, v.22, n.1, p.60-67, 2002.

FURLANI, C.E.A.et al. Desempenho operacional de uma semeadora-adubadora de precisão, em função do preparo do solo e do manejo da cobertura de inverno. Engenharia Agrícola, Jaboticabal, v.24, n.2, p.388-395, 2004.

FURLANI, C.E.A. et al Exigências de uma semeadora-adubadora de precisão variando a velocidade e a condição da superfície do solo. Ciência Rural, Santa Maria, v.35, n.4, p.920-923, 2005 a.

FURLANI, C.E.A.; LOPES, A.; SILVA, R.P. Avaliação de semeadora-adubadora de precisão trabalhando em três sistemas de preparo do solo. Engenharia Agrícola, Jaboticabal, v.25, n.2, p.458-464, 2005b.

FURLANI, C.E.A.et al. Semeadora-adubadora: exigências em função do preparo do solo, da pressão de inflação do pneu e da velocidade. Revista Brasileira de Ciência do Solo, Viçosa, v.32, n.1, p.345-352, 2008.

GAMERO, C. A. Efeitos dos tipos de preparo sobre características do solo e da cultura do milho (Zea mays L.). 1985. 120 f. Tese (Doutorado em Agronomia / Solos e Nutrição de Plantas) - Escola Superior de Agricultura "Luiz de Queiroz”, Universidade de São Paulo, Piracicaba.

JONES, J. N. et al. The no-tillage system for corn (Zea mays L.). Agronomy Journal, Madison, v. 60, n.1, p. 17-20, 1968.

LEVIEN, R. et al. Semeadura direta de milho com dois tipos de sulcadores de adubo, em nível e no sentido do declive do terreno. Ciência Rural, santa Maria, v.41, n. 6, p. 996-1002, 2011.

MAHL, D. et al. Demanda energética e eficiência da distribuição de sementes de milho sob variação de velocidade e condição de solo. Engenharia Agrícola, Jaboticabal, v.24, n.1, p.150-157, 2004.

MAZUCHOWSKI, J. Z.; DERPSCH, R. Guia de preparo do solo para culturas anuais mecanizadas. Curitiba: Associação de Crédito e Extensão Rural do Estado do Paraná, 1984. 68 p.

MODOLO, A.J.et al. Força de tração necessária em função do número de linhas de semeadura utilizadas por uma semeadora-adubadora de precisão. Engenharia Agrícola, Laboticabal, v.25, n. 2, p.465-473, 2005.

NAGAOKA, A.K.et al. Avaliação das características operacionais de um conjunto trator-semeadora em três sistemas de manejo do solo e três velocidades na operação de semeadura da cultura do feijão (Phaseulus vulgaris). In: Congresso Brasileiro de Engenharia Agrícola. 35., 2006. Anais... João Pessoa, SBEA, 2006. CD-ROM

ORTIZ-CAÑAVATE, J. Las maquinas agricolas y su aplicación. Madrid: Mund-Prensa, 1980. 490 p.

SILVA, A.R.B. Diferentes sistemas de manejo do solo e espaçamentos na cultura do milho (Zea mays L.). 2004. 147f. Tese (Doutorado em Agronomia / Energia na Agricultura) - Faculdade de Ciências Agronômicas, Universidade Estadual Paulista, Botucatu.

SILVA, P.R.A.; BENEZ, S.H. Avaliação de forças resultantes de mecanismos sulcadores de semeadorasadubadoras de plantio direto. Energia na Agricultura, Botucatu, v.20, n.2, 2005. Disponível em: <http://200.145.140.50/html/CD REVISTA ENERGIA vol2/artigos.htm>. Acesso: em 13 maio 2011. 